\title{
Bender, Steffen, Der Burenkrieg und die deutschsprachige Presse, Wahrnehmung und Deutung zwischen Bureneuphorie und Anglophobie 1899-1902
}

\section{Fanny Dufétel-Viste}

\section{OpenEdition}

\section{Journals}

Édition électronique

URL : http://journals.openedition.org/ifha/2226

DOI : $10.4000 /$ ifha.2226

ISSN : 2198-8943

\section{Éditeur}

IFRA - Institut franco-allemand (sciences historiques et sociales)

\section{Référence électronique}

Fanny Dufétel-Viste, "Bender, Steffen, Der Burenkrieg und die deutschsprachige Presse, Wahrnehmung und Deutung zwischen Bureneuphorie und Anglophobie 1899-1902 », Revue de I'IFHA [En ligne], Date de recension, mis en ligne le 01 janvier 2010, consulté le 22 septembre 2020. URL : http:// journals.openedition.org/ifha/2226 ; DOI : https://doi.org/10.4000/ifha.2226

Ce document a été généré automatiquement le 22 septembre 2020.

(CIFHA 


\title{
Bender, Steffen, Der Burenkrieg und die deutschsprachige Presse, Wahrnehmung und Deutung zwischen Bureneuphorie und Anglophobie 1899-1902
}

\author{
Fanny Dufétel-Viste
}

1 La politique navale de l'Allemagne à la veille de la Première Guerre mondiale a fait l'objet d'analyses multiples visant à démontrer comment elle contribua à créer la défiance entre l'empire de Guillaume II et l'Angleterre. La guerre des Boers qui opposa ces derniers, descendants de Néerlandais, à l'Angleterre entre 1899 et 1902 en Afrique du Sud et où l'Allemagne, puissance coloniale présente en Afrique, joua un rôle ambigu, est en revanche un facteur de distanciation moins souvent considéré.

2 C'est à cet événement que s'intéresse S.B. dans son ouvrage paru en 2009 sur " La guerre des Boers et la presse germanophone, perception et interprétation entre euphorie pro-Boers et anglophobie 1899-1902 ». Ainsi que l'indique le titre, l'auteur s'y attache à mettre en perspective la manière dont la presse allemande a représenté et interprété la guerre des Boers et la manière dont elle s'est émancipée alors du pouvoir politique pour peser sur l'opinion publique. À partir d'archives et d'une quarantaine de quotidiens et magazines allemands et autrichiens, l'auteur dégage des grilles de lecture des différents médias imprimés de l'époque selon leur bord politique et le public visé. D'un point de vue méthodique, l'auteur souligne avec justesse les limites d'une telle approche : les réactions des lecteurs restent par nature largement inconnues et tous les quotidiens ne sont pas engagés au même degré selon qu'ils traitent de politique, d'économie ou même de littérature. Le conflit n'en reste pas moins un marqueur important : pas un quotidien de l'époque ne l'ignore totalement.

3 La guerre des Boers fut en effet d'abord un " événement médiatique " (deuxième partie) qui donna lieu à des interprétations diverses et des conclusions diverses 
(troisième partie). Les journaux les plus conservateurs y virent ainsi la lutte entre un impérialisme anglais assoiffé de diamants et de pouvoir et un peuple fier luttant pour son indépendance, voire entre une nation industrialisée sans âme et une population vivant encore la vie simple et vertueuse d'une société agricole des temps anciens. S'y ajoutait un aspect racial pour les nationalistes les plus radicaux puisque les Boers étaient vus comme une lointaine branche allemande. Les journaux libéraux et ceux plus proches du pouvoir, plus soucieux de "Realpolitik », y distinguèrent avant tout la lutte prosaïque entre deux impérialismes et, pour certains, tentèrent de se tenir à égale distance de toute diabolisation de l'Angleterre comme de toute idéalisation de Boers jugés anachroniques et même archaïques dans leur mode de vie. Les journaux de tendance socialiste adoptèrent une grille de lecture essentiellement économique, voyant dans ce conflit armé entre deux puissances un symptôme de plus de l'état de déliquescence de la société capitaliste.

Ce conflit aura des répercussions extérieures et intérieures importantes pour le Reich allemand (quatrième partie). Guillaume II, en conformité avec son opinion publique, s'était dans un premier temps montré favorable à la cause des Boers avant de se figer dans une attitude de neutralité que lui reprochèrent de plus en plus certains journaux allemands. Dans le même temps s'accroissait en Angleterre la méfiance envers une Allemagne prétendument neutre mais dont la presse se montrait si hostile et agressive envers l'Angleterre. L'auteur analyse très finement comment, au fil d'incidents répétés et divers comme la visite avortée du président du Transvaal Paul Krüger à Berlin, Guillaume II et le gouvernement allemand se retrouvèrent piégés dans une situation inconfortable entre l'Angleterre et une opinion publique et des médias marqués majoritairement par une forte sympathie pour la cause des Boers.

Cette étude met parfaitement en lumière - jusque dans l'épilogue de la Première Guerre mondiale (cinquième partie) - comment un événement géographiquement lointain devint le réceptacle de toutes les projections politiques et idéologiques possibles et contradictoires dans les médias. À ce titre, elle n'est pas seulement intéressante pour ce qui touche à la relation ambiguë entre l'Allemagne et l'Angleterre à la veille de la guerre. Elle est également très éclairante en ce qui concerne l'action de la presse et ses lignes de conflit internes au début du XXe siècle en Allemagne, et plus largement la lecture qui peut être faite de l'histoire immédiate par les médias.

Fanny Dufétel-Viste (Université de Rennes II) 